gestão e participação

1. Apresentação;

2. Dimensão politica da participação;

3. Participação em saúde - origem e estado atual da

temática;

4. Dificuldades e potencialidades da participação em

satide.

\section{Mitos e potencialidades da participação em saúde}

Moema Miranda de Siqueira Da UFMG

Adelaide M. Coelho Baeta

Da UFMG

\section{APRESENTAÇÃO}

0 presente trabalho pretende discutir a temática da participação em saúde a partir de um estudo sobre normas de visitas a pacientes hospitalizados em Belo Horizonte.

Embora a pesquisa empírica tenha sido realizada a micronível utilizaram-se na analise conceitos macrossociais como referenciais teóricos.

Os dados preliminares sugerem as dificuldades encontradas no processo de participação quando os indivíduos estão inseridos na rotina cotidiana, tendendo a reproduzir a ideologia dominante.

No entanto, a participação como processo político $\epsilon$ defendida justamente por seu potencial emancipador.

\section{DIMENSÃO POLITICA DA PARTICIPAÇÃO}

Entende-se, aqui, participação como um processo eminentemente politico. Isto supre que todas as pessoas afetadas por uma determinada decis̃̃o devam estar de algum modo envolvidas no processo decisório. Esta questão remete ao conceito de soberania popular, que implica a consciéncia de que toda pessoa é capaz de escolher o que é bom para ela, dispensando autoridades - especialistas de "saber reconhecido" que thes digam quais as suas reais necessidades (Campos, 1980).

A participação popular supae, portanto, a coexistenncia da racionalidade comunicativa - em que predominam os interesses emancipatórios, consubstanciados na liberdade de expressão e comunicação da vontade popular - e da racionalidade instrumental - que enfatiza os interesses técnicos (Freitac, 1980). Assim, deverá ser utilizado o conhecimento técnico em favor das maiorias populares, cuja experiéncia e conhecimento informal podem contribuir para subordinar a tecnica. a interesses mais gerais.

Quando se fala de participação numa estrutura burocrática de poder, fica claro que esta participaçăo é definida a priori, por normas e regras que constituem o sistema de direito, o que não elimina tambem a possibilidade de que até mesmo essas normas sejam freqüentemente violadas.

Acreditase, todavia, que a prática participativa aos poucos pode alterar as relaçóes de poder e mudar as dimensōes e capacidade de escolha cole tiva (Sellier, 1976).

\section{PARTICIPAÇÃO EM SAŨDE ORIGEM E ESTADO ATUAL DA TEMÁTICA}

Quando o "arranque" desenvolvimentista dos países subdesenvolvidos mostrou-se incapaz de reduzir automaticamente as diferenças sociais e assegurar a integração da maioria da população ao mercado e d cidadania, na área de saúde ocorre um deslocamento da preocupação teórica com $o$ estado de saúde para a questão dos servifos de sauide (Cardoso, 1973). Procuram-se novas estratégias capazes de garantir a extensão de serviços de saúde às populaçôes excluídas desse consumo.

Um exemplo marcante é o da chamada "medicina comunitaria". Oriunda dos EUA, ali surgiu como resposta ds tensóes sociais causadas pelo movimento dos direitos civis e pelos conflitos raciais, tendo por alvo principalmente as populaçres dos guetos (Donnangelo, 1976).

Transplantada para a America Latina, aqui difundiuse com o apoio da Organização Mundial de Saúde e Organização Panamericana de Saúde. No Brasil, começando pela universidade (Londrina, 1976), através de projetos académicos, financiados por organismos internacionais (Fundação Ford, Fundaçăo Rockfeller etc.), atingiu o Estado, com projetos como o do Șistema Integrado de Prestação de Serviços de Saúde do Norte de Minas (1974) e o Programa de Interiorização das Açóes de Saúde e Saneamento (Piass, 1976). Aparece, em uma de suas dimensóes, como prática alternativa paralela à organização dominante da assisténcia médica. Como projeto, implica a ampliação de cobertura de assisténcia médica, atraves de técnicas simplificadas, tratamento de doenças mais comuns, incorporando a mấo-de-obra local aos serviços, o que é visto como "participaçăo comunitária".

Analisando sua evolução teórica, Pellegrini Filho et alii (1979), mostram que, em seus primórdios, o interesse pelo tema esteve associado aos estudos sobre urbanização acelerada do fim da II Guerra Mundial e que, no Brasil, embora na política institucional os pre. ceitos se referissem especificamente ds populaçðes rurais, 
verificou-se seu desdobramento a outros setores da população urbana considerados "marginais".

Os autores citados concluem afirmando que tais propostas têm sua fundamentação nos modelos "psicossócio-cultural" e "dual" da teoria comportamentalista, que propðem como solução para a marginalidade açōes sobre os grupos marginais, mantendo-se intacta a estrutura social, o que transforma as açōes comunitárias èm praticas de controle social.

Sem reproduzir as características meramente assistencialistas ou paternalistas, tradicionais nos programas de "ajuda aos pobres", os programas de ação comunitária, segundo os autores, pretenderiam, através da participação, despertar os grupos populacionais para melhor aproveitarem seus recursos, adotando um padrão considerado normal de integração dentro de estrutura social (Pellegrini Filho et alii, 1979, p. 221).

Traduzindo a concepção de que os problemas locais são locais não somente em sua expressão, mas também em sua origem, esvaziam a dimensáo estrutural dos problemas locais e restringem a participação ao nível local, sem abrir canais que permitam uma participação ao nivel das grandes decisóes de carater nacional.

Embora com a ressalva de que a análise do movimento da medicina comunitária exigiria melhor fundamentação teórica das relaçóes saúde/estrutura social, Jairnilson Paim (1982) é menos radical que os autores anteriores. Inicialmente, mostra que, quando a proposta é assimilada pelo discurso oficial brasileiro, nem todos os componentes são igualmente incorporados.

Acompanhando no tempo a trajetória da temática participação comunitária, nota que ela varia, da mesma forma que a regionalização dos serviços de saúde, em decorrência de flutuaçőes conjunturais. Acredita que, depois das experiências a nivel da universidade e aquelas de nivel regional financiadas por organismos intemacionais, o PIASS, apesar de todas as restriçoes que lhe podem ser justamente imputadas, contribuiu para a difusão de ideologias modernizantes no interior das instituiçбes de saúde, sendo, pelos relatos conhecidos, potencialmente participativo.

Outro marco na trajetória da temática participação no discurso oficial brasileiro foi a Conferência de Alma Alta (OMS/Unicef, 1978). O Prev-Saúde, divulgado em 1980, surgiu de recomendaçð̄es dessa Conferência. Além de ampliar, em extensão e apoio financeiro, as metas do PIASS, chegou a apresentar objetivos de reordenamento do setor saúde, incorporando temáticas de medicina comunitária, inclusive a categoria de participação comunitária. No entanto, as pressð̃es dos empresários médicos impuseram-lhe tal sorte de mutilaçoes que o programa sequer conseguiu atingir suas metas de extensão de cobertura (Paim, 1982). Além do mais, a análise ainda que superficial do conteúdo dos documentos dessa fase sugere que a participação comunitária era entendida como o envolvimento da população com a execução dos serviços e a preocupação com a "conscientização" sobre os benefícios decorrentes dos programas. $\mathrm{Na}$ pratica, segundo Teixèira, a participação nada mais significou que colaboração com o Programa (Teixeira et alii, 1979).

Merecem ainda referência alğumas experiências realizadas entre nós sob os auspícios da Igreja Católica.
Na fase de maiores restrições aos canais de expressão da sociedade civil, a Igreja passou a constituir um espaço de discussão e prática democrática (Bohadana, 1982).

Desde 1967, com o Projeto Aratuba (Ceara, 1967), a Igreja Católica estimulou o desenvolvimento de experiências em diferentes estados do país, do Norte (Perpétuo Socorro, Amapa) ao Sul (Acapuna, Parana), passan. do pelo Nordeste (Recife, Ceára), Centro-Oeste (Goiás Velho) e Centro-Sul (Nova Iguaçu, RJ; Nova Holanda, RJ; Campinas, SP; Vale do Ribeira, SP; favelas do Vidigal, do Chapeu, Mangueira e Guararapes, RJ). $O$ relato dessas experiências permite identificarem-se alguns aspectos diferenciais em relação aos projetos financiados por agências internacionais, ou organismos estatais.

- Estes últimos, de natureza freqüentemente mais acadêmica, privilegiam as açőes de saúde e a extensão de cobertura, enquanto os projetos da Igreja demonstram uma preocupação maior com a mobilização e organização da comunidade.

No caso de Cabuçu (Nova Iguaçu, RJ), foi constatado que a dinâmica dos encontros foi deixando de ser uma simples troca de experiências em torno de assistência médica para se tornar gradualmente uma troca de experiências de práticas comunitárias.

Esta evolução permite que se vislumbre com mais otimismo o futuro da participação em saúde.

No entanto, para- evitar ingenuidades ideológicas e e simplismos sem significação cientffica, o modelo teorico de participação tem de reconhecer que, mesmo em situaçбes formalmente democráticas, ocorre diferencial de poder entre os grupos sociais e o uso desse poder introduz viés nas decisōes referentes a alocação de recursos. Portanto, a participação por consenso traz dificuldades, ainda que se reconheça que os problemas a nível do consumo têm sua origem no âmbito da produção.

O caminho é buscar formas de expressão para que também os grupos ora "marginais" possam influir com os outros grupos no contínuo processo de mudança por que passa a estrutura social.

Para alguns mais otimistas, o próprio planejamento tem potencial para servir ds forças democráticas e populares (Paim, 1982).

Embora historicamente venha sendo usado autoritariamente, não existe associação linear entre planejamento/ideologia tecnocrática.

Além das técnicas que o confirmam, ele é a expres. são de políticas de Estado, articulando-se, portanto, com as práticas sociais concretamente apresentadas na história.

A comprovação de sua ineficiéncia nos moldes da "modemização conservadora" vem gerando uma crise de legitimidade, que poderá ser aproveitada no sentido de se usar $o$ potencial de mobilização política do plano. $\mathrm{Na}$ busca de bases sociais o planejamento deverá voltar se para a redistribuição.

Tal papel não é fácil. De um lado, devem se reduzir burocraticamente a heterogeneidade e as diferentes necessidades e aspiraçōes da população. De outro, deve-se conceder maior participação, em oposição ao gerencialismo burocrático, à população envolvida pelos planos e proje. tos. A busca de canais de expressão que permitam aos diferentes grupos sociais influírem nas definiçoes de políticas voltadas para suas reais necessidades parece estar surtindo efeito. 
Entre os movimentos sociais emergentes, iniciados com os trabalhadores uretalurgicos do $\mathrm{ABC}$ paulista, no in ício de 1978, envolvendo a área de saude, sobressaem-se a criação do Departamento Intersindical de Estudo e Pesquisas de Saúde e dos Ambientes de Trabalho (Diesat) em São Paulo, os encontros populares pela Saúde, em São Paulo e no Rio de Janeiro, e a atuação agressiva de sindicatos médicos em vários estados. Tais fatos demonstram a capacidade de arregimentaçăo da sociedade civil em direção a uma polf́tica emancipadora, que implica novas formas de produzir, receber e distribuir bens a nível nacional, entre todas as areas e grupos sociais. $E$ as decisőes sobre necessidades básicas terão de ser definidas em novos moldes (Siqueira, 1981).

Concluindo, constata-se que a participação em saúde, para ser efetivamente emancipadora, deve desenvolver-se nos marcos de uma real participação da comunidade em todos os setores de sua vida, enquanto coletividade, entendendo que as condiçóes da saúde de cada um relacionamse is condiçōes gerais de vida a que estão expostas suas comunidades.

A participação, portanto, não é exclusiva das questoes de saude, mas deve envolver o conjunto das necessidades de consumo coletivo, atraves do direito a voz e açao dos participantes na totalidade dos problemas que the dizem respeito (Pellegrini Filho et alii, 1979).

Para Bohadana, a "questæo saúde", por sua abrangenncia, apresenta um grande potencial de irradiação no processo participativo - razáo pela qual deve ser melhor aproveitada (Bohadana, 1982).

\section{DIFICULDADES E POTENCIALIDADES DA PARTICIPAÇĀO EM SAĈDE}

0 enfoque adotado até aqui pretende discutir a temática participação numa macroperspectiva, inclusive enfatizando que a participação em saúde só tem sentido na medida em que se insira em um processo mais amplo de participaça política.

Sem negar quaisquer das colocaçoes anteriores, as consideraçóes que são feitas a seguir decorrem da constatação de que uma efetiva democratização da saude deverá atingir a organização de seus serviços, através de uma descentralização real, capaz de viabilizar uma auténtica participação da população em diferentes níveis e instâncias do sistema. Sua operacionalização supóe representantes e deve estar alerta para que a solução não seja meramente administrativa ou "estatizante". Para tanto, tem de canalizar as reivindicaçōes e proposiçoes dos beneficiarios, transformando-os em voz e voto em todas as instâncias (Cebes, 1980).

Embora referidas a um micronível, as observaçós preliminares, baseadas em uma pesquisa relativa ds normas sobre visitas a pacientes hospitalizados, sugerem as dificuldades e potencialidades do processo de participação nas decisoes sobre saúde.

O objetivo da pesquisa foi levantar as principais normas institucionais relativas a visitação e acompanhamento de pacientes hospitalizados, tendo em vista ds justificativas de natureza administrativa, de saúde, psicológica, social e religiosa, bem como as expectativas e opinioes do pacientes, familiares, profissionais de saúde e funcionários administrativos sobre essas normas. Paralelamente, procura analisar as possíveis contradiçōes dessas logicas, entre si e em relação às suas justificativas.

Sabe-se que a hospitalização é um recurso de atenção médica que envolve aspectos significativamente contraditórios. Se, de um lado, oferece ao paciente condições mais propícias à superação de seu problema de saú. de, por outro ocasiona uma vivência traumatizante para o paciente e seus familiares. Além dos desequilíbrios biopsíquicos decorrentes da própria doença, a internação hospitalar separa o doente de seu cotidiano e de suas ligaçōes sociais e afetivas fundamentais. As visitas, em primeira instância, permitem a manutenção de elos com o exterior e de relaçōes afetivas básicas. Podem, no entanto, ocasionar prejuízo ao tratamento do paciente e riscos ao visitante. Não são raras as constataçōes dos profissionais de saúde relativas ao agravamento do estado físico do paciente, em decorrência de cansaço, acometimento de infeç̧бes secundárias, ingestão de alimentos incompat f́veis com o quadro clínico ou alteração de condições psíquicas imputadas às visitas a esses pacientes.

Por outro lado, constantemente enfatiza-se o risco de contaminação, tanto originária do ambiente hospitalar para as visitas, quanto destas para o hospital e mais particularmente para os pacientes.

Muitas vezes a necessidade de visitar ou acompanhar um membro da famnlia doente pode representar sobrecarga e até ónus financeiros pesado. Além do mais, as visitas em hospitais exigem o desenvolvimento de uma série de atividades e rotinas que sobrecarregam sobremaneira os serviços administrativos. Os serviços de portaria e informaçőes devem ser multiplicados nos horários de visita. $O$ tránisito intemo se avoluma, alterando as condiçóes de silêncio e de locomoç̃̃o do pessoal e material hospitalar. E mesmo o controle de material e medicamento tem de ser aumentado.

Freqüentemente, observam-se em hospitais conflitos, decorrentes das normas sobre visitas e acompanhantes $e$ os interesses das diversas partes envolvidas, agravadas pela utilização de padroes e justificativas de outros paises, com cultura e valores diferentes dos nossos.

$\mathrm{Na}$ pesquisa, inicialmente, supôs-se que as normas seriam diferentes conforme a categoria de cobertura do paciente: particular, previdenciário e indigente. Admitiu-se como hipotese tamberm que os profissionais de satude, os chefes administrativos, os visitantes e os pacientes teriam percepçces diferentes a respeito das mesmas normas. Assim, foram entrevistadas amostras destes quatro estratos e, dentre os pacientes, os previdenciarios, particulares e indigentes.

Embora sejam ainda insuficientes para uma extrapolação estatística, os dados já levantados parecem indicar algumas tendências interessantes. Em relação ds percepçð̋es dos profissionais de saúde, chefes administrativos, pacientes e visitantes, nota-se uma certa homogeneidade nas respostas dos dois primeiros estratos e nas dos dois tltimos. Assim, por exemplo, tanto os profissionais de saúde (médicos e pessoal de enfermagem) quanto os chefes administrativos, em sua maioria, acreditam que as visitas são mais maléficas que beneficas aos pacientes, alguns afirmando mesmo que chegam a ser somente maleficas. Justificam alegando tumulto no hospital nos momentos de visita, agudização do sentimento de perda, 
principalmente entre as crianças, valorização da própria doença etc. $\mathbf{O}$ oposto ocorre nos grupos de visitantes e pacientes. A maioria quase absoluta opina que as visitas só ajudam aos pacientes, achando os demais que ajudam mais que atrapalham.

Em relação à normas existentes, embora diferentes conforme a categoria de cobertura - particular, previdenciária e indigente - não houve grandes questionamentos por parte dos pacientes nem dos visitantes. Parece estar sendo eficiente a "Iógica da ocultaçăo", na medida em que apaga as diferenças sociais e as considera legítimas. Da mesma forma, enquanto se constatou que as normas foram elaboradas em sua totalidade pelos profissionais de saúde e/ou pelos chefes administrativos, estes grupos concordam que elas devam continuar sendo feitas por eles, abrindo uma única exceção para o horario de visitas, quando talvez as famlias pudessem ser ouvidas. Contrariamente ao que se esperava, também os pacientes e os visitantes, embora estes com menos intensidade, aceitam que as normas devam ser elaboradas pelos profissionais de saude (principalmente pelo médico) e chefes administrativos.

A indicação do visitante e do paciente como participantes do processo e ainda insignificante estatisticamente.

Embora se tenda a considerar o autoritarismo apenas através de seus signos mais visíveis - o uso de força, a repressão, etc. - a sua forma mais sutil e talvez mais eficiente. A idéia de razão e de racionalidade comandam a legitimação da autoridade (Chauí, 1982) e é ela que parece explicar a tendência dos dados aqui analisados. A 'ideologia é um conjunto lógico, sistemático e coerente de representação (idéias e valores) e de normas ou regras de conduta, que indicam e prescrevem aos membros da sociedade o que devem pensar, o que devem valorizar e como devem valorizar, o que devem sentir e como devem sentir, o que devem fazer e como devem fazer" (Chaur, 1981, p. 113-4).

Ao nível das respostas, como adverte Thiollent (1980), mesmo os membros das classes populares podem permanecer no "autoritarismo" ou aderir a qualquer forma moral dominante ou acreditar em mito, sem que isto constitua uma consciência especiffica. Na fala de indivíduos inseridos na rotina cotidiana, seria mesmo surpreendente encontrarse um sistema de opinião divergente do senso comum e da ideologia dominante. Para o mesmo autor, a coleta de opinióes, quando mantendo os entrevistados na passividade do dia-a-dia, tende a comprovar os efeitos da dominaçáo ou a apreen. der certos aspectos de reprodução simbolica.

\section{REFERENCLAS BIBLIOGRÁFICAS}

Arouca, Ana Maria T. Análise das determinantes de condições de saúde da populaçáo brasileira. In: Guimaráes, Reinaldo, org. Saúde e medicina no Brasil; contribuiça para um debate. Rio de Janeiro, Graal, 1978.
Bohadana, Estrella. Experiências de participaçđo popular nas açóes de saúde. In: Saúde e trabalho no Brasil. Petrópolis, Vozes, 1982.

Campos, Anamaria. Um novo modelo do planejamento para uma nova estratégia de desenvolvimento. Revista de Administração Pública, 14 (3): 27-45, jul./set. 1980.

Cardoso,- Fernando H. O modelo politico brasiletro. 2 ed., Sáo Pálo, Difusáo Européia do Livro, 1973.

Cebes. A questáo democrática na área de saúde. Documento apresentado yo I Simpósio sobre Política Nacio. nal de Saúde na Câmara Federal. Saúde em Debate, 9: 11-3,jan./mar. 1980.

Chauí, Marilena. $O$ que é ideologia. 2. ed., São Paulo, Brasiliense, 1981.

Cultura do povo e autoritarismo das elites. In: Valles, Edenio \& Queiroz, Jose J., org. A cultura do povo. São Paulo, Educ., 1982.

Donnangelo, Maria Cecrlia. Saride e sociedade. Sฐ̃o Paulo, Duas Cidades, 1976.

Freitac, Bárbara et alii. Habermas. Sao Paulo, Ảtica, 1980.

Gerth, H.H. \& Mills, Wright C., org. e intr. Ensaios de sociologia de Max Weber. Rio de Janeiro, Zahar, 1967.

Merhy, Emerson. Democracia e saude. In: Saude em Debate, 4: 7-13, jul./set. 1977.

OMS/Unicef. Cuidados primários de saude. Relatório da Conferência Intemacional sobre Cuidados Primários da Saúde. Alma Alta, URSS, set. 1978.

Paim, Jaimilson S. \& Almeida Filho, Naomar. Introdufăo à critica do planejamento de saúde. Salvador, Universidade Federal da Bahia, 1982, mimeogr.

Pellegrini Filho, Alberto et alii. A medicina comunitária, a questão urbana e a marginalidade. In: Guimarães, Reinaldo, org. Saude e medicina no Brasil; contribuição para um debate. Rio de Janeiro, Graal, 1979.

Sellier, François. Les relations industrielles, Paris, PUF, 1976.

Singer, Paul et alii. Prevenir e curar; o controle social através dos serviços de saúde. Rio de Jạneiro, Forense Universitária, 1978.

Siqueira, Moema M. de. Estedo e burocratização da medicina. Belo Horizonte, UFMG, 1981, mimeogr.

Teixeira, C.F. et alii. PIASS - uma alternativa para a crise? Salvador, Universidade Federal Bahia, 1979.

Thiollent, Michel. Critica metodológica, investigação social e enquête operuiria. São Paulo. Pólis. 1980. 